Check for updates

Cite this: RSC Adv., 2017, 7, 48841

Received 4th September 2017

Accepted 10th October 2017

DOI: $10.1039 / c 7 r a 09841 c$

rsc.li/rsc-advances

\title{
Thioester-functionalised and oxime-based hexametallic manganese(III) single-molecule magnets $\dagger$
}

\begin{abstract}
Carlos Rojas-Dotti and José Martínez-Lillo (D) *
Two novel hexametallic $\mathrm{Mn}^{\prime \prime \prime}$ complexes of formulae $\left[\mathrm{Mn}_{6}\left(\mu_{3}-\mathrm{O}\right)_{2}\left(\mathrm{H}_{2} \mathrm{~N}-\mathrm{sao}\right)_{6}(3-\text { atpa })_{2}(\mathrm{EtOH})_{6}\right]$. $2 \mathrm{EtOH} \cdot 2 \mathrm{H}_{2} \mathrm{O}$ (1) and $\left[\mathrm{Mn}_{6}\left(\mu_{3}-\mathrm{O}\right)_{2}\left(\mathrm{H}_{2} \mathrm{~N} \text {-sao }\right)_{6}(6 \text {-atha })_{2}(\mathrm{EtOH})_{6}\right] \cdot 6 \mathrm{EtOH} \quad$ (2) $\left[\mathrm{H}_{2} \mathrm{~N}-\mathrm{saoH}_{2}=\right.$ salicylamidoxime, 3-hatpa $=3$-(acetylthio)propionic acid, 6-hatha $=6$-(acetylthio)hexanoic acid] have been synthesised by using thioester-carboxylate ligands and magnetostructurally characterised. 1 crystallises in the triclinic system with space group $P \overline{1}$ and 2 crystallises in the monoclinic system with space group $P 2_{1} / c$. The study of the $d c$ and ac magnetic susceptibility reveals single-molecule magnet behaviour for both compounds with spin-ground states $S=12$ and $S=4$ for 1 and 2, respectively. Hence, 1 and 2 are new members of the oxime-based family of $\left[\mathrm{Mn}_{6}\right]$ single-molecule magnets, containing the thioester group functionalisation, which could be used to connect devices in molecular spintronics studies.
\end{abstract}

\section{Introduction}

Single-Molecule Magnets (SMMs) have attracted much interest because of their spin properties and potential applications, and have also been considered a fundamental link between two novel scientific disciplines, molecular spintronics and molecular electronics. ${ }^{1-4}$ In recent years, great research effort has been devoted to the synthesis of single-molecule systems, with large magnetic anisotropies, and their functionalization, which is made with functional groups convenient to connect suitable SMMs to junction devices or to perform their grafting on surfaces of Si or Au substrates; ${ }^{5-10}$ in many cases, looking for the improvement of their magnetic properties, ${ }^{7,8}$ the control of the nanoscale organization ${ }^{\mathbf{1 0}}$ or simply to get a reliable description of the electronic structure of the investigated system. ${ }^{\mathbf{1 1}}$

Thioesters-based ligands have proven to be particularly useful to get derivatised and suitable SMMs for this research field (Scheme 1). Indeed, $\left[\mathrm{Fe}_{4}^{\mathrm{III}} \mathrm{Ni}_{4}^{\mathrm{II}}\right]$ cages have been connected to junction devices, ${ }^{9}$ besides that, complexes such as the wellknown $\left[\mathrm{Mn}_{8}^{\mathrm{III}} \mathrm{Mn}_{4}^{\mathrm{IV}}\right]$ system and the $\left[\mathrm{Fe}_{4}^{\mathrm{III}}\right]$ and $\left[\mathrm{Fe}_{3}^{\mathrm{III}} \mathrm{Cr}^{\mathrm{III}}\right]$ complexes with star-like structures have been grafted on $\mathrm{Au}$ surfaces after being thioester-functionalised. ${ }^{\mathbf{1 0}}$

Oxime-based hexanuclear $\mathrm{Mn}^{\mathrm{III}} \mathrm{SMMs}$ have intensively been studied in the field of molecular magnetism. ${ }^{12-16}$ In these

Instituto de Ciencia Molecular (ICMol), Departament de Química Inorgànica, Universitat de València, c/ Catedrático José Beltrán 2, Paterna, 46980, Valencia, Spain. E-mail:f.jose.martinez@uv.es

$\dagger$ Electronic supplementary information (ESI) available: Fig. S1 and S4. CCDC 1568972 and 1568973. For ESI and crystallographic data in CIF or other electronic format see DOI: 10.1039/c7ra09841c systems, the magnetic exchange between $\mathrm{Mn}^{\mathrm{III}}$ ions depends basically on the $\mathrm{Mn}-\mathrm{N}-\mathrm{O}-\mathrm{Mn}$ torsion angles, they possess generally spin ground states varying from 4 to 12 , and the anisotropy energy barriers vary from 24 to 86 K. ${ }^{\mathbf{1 2 - 1 6}}$ Some of these $\left[\mathrm{Mn}_{6}^{\mathrm{III}}\right]$ SMMs have also been grafted on $\mathrm{Au}$ surfaces and studied, as thiophene-carboxylate $\left[\mathrm{Mn}_{6}^{\mathrm{III}}\right]$ derivatives. ${ }^{7,8}$ Nevertheless, no thioester-functionalised $\left[\mathrm{Mn}_{6}^{\mathrm{III}}\right]$ compound has been reported up to date.

Herein we report the synthesis and magnetostructural characterisation of two novel hexanuclear $\mathrm{Mn}^{\mathrm{III}}$ compounds of formulae $\left[\mathrm{Mn}_{6}\left(\mu_{3}-\mathrm{O}\right)_{2}\left(\mathrm{H}_{2} \mathrm{~N}-\mathrm{sao}\right)_{6}(3 \text {-atpa })_{2}(\mathrm{EtOH})_{6}\right] \cdot 2 \mathrm{EtOH} \cdot 2 \mathrm{H}_{2} \mathrm{O}$ (1) and $\left[\mathrm{Mn}_{6}\left(\mu_{3}-\mathrm{O}\right)_{2}\left(\mathrm{H}_{2} \mathrm{~N}-\mathrm{sao}\right)_{6}(6 \text {-atha })_{2}(\mathrm{EtOH})_{6}\right] \cdot 6 \mathrm{EtOH}$ (2) $\left[\mathrm{H}_{2} \mathrm{~N}\right.$-saoH $\mathrm{S}_{2}=$ salicylamidoxime, 3-hatpa $=3$-(acetylthio)propionic acid, 6-hatha $=6$-(acetylthio)hexanoic acid]. 1 and 2 are the first reported structures of thioester-functionalised $\left[\mathrm{Mn}_{6}^{\mathrm{III}}\right]$ SMMs.

A)<smiles>CC(=O)SCCC(=O)O</smiles>

B)<smiles>CC(=O)SCCCCCC(=O)O</smiles>

Scheme 1 Molecular structures of: (A) 3-(acetylthio)propionic acid and (B) 6-(acetylthio)hexanoic acid. 


\section{Results and discussion}

Synthetic procedure

By reacting $\mathrm{MnCl}_{2} \cdot 4 \mathrm{H}_{2} \mathrm{O}$ with the salicylamidoxime ligand in the presence of the desired $S$-acetyl-carboxylic acid and $\mathrm{NEt}_{3}$ we obtain a dark green microcrystalline solid of hexametallic $\mathrm{Mn}^{\text {III }}$ complexes in satisfactory yields. Good-sized crystals were obtained from concentrated solutions of the microcrystalline solid in ethanol by layering them with acetone (1) and ethanol (2) (see Experimental section). Hence, this is a straightforward synthetic procedure to add the $S$-acetyl function $\left[\mathrm{CH}_{3}-\mathrm{C}(\mathrm{O})-\mathrm{S}-\right]$ to the well-known family of $\left[\mathrm{Mn}_{6}\right]$ complexes (Fig. 1, 2, S1 and $\mathrm{S} 2 \dagger)$.

\section{Description of the crystal structures of 1 and 2}

Compound $\mathbf{1}$ crystallises in the triclinic system with space group $P \overline{1}$, and compound 2 crystallises in the monoclinic system with space group $P 2_{1} / c$ (Table 1$)$. Their structures are made up of neutral hexanuclear $\left[\mathrm{Mn}_{6}\right]$ complexes together with water (1) and ethanol (1 and 2) molecules of crystallisation, which are self-assembled through hydrogen-bonding interactions (see Fig. 3 and $\mathrm{S} 3 \dagger$ ).

Each hexanuclear $\left[\mathrm{Mn}_{6}\left(\mu_{3}-\mathrm{O}\right)_{2}\left(\mathrm{H}_{2} \mathrm{~N}-\mathrm{sao}\right)_{6}(\mathrm{~L})_{2}(\mathrm{EtOH})_{6}\right][\mathrm{L}=3-$ acetylthiopropionate (3-atpa) in $\mathbf{1}$ and 6-acetylthiohexanoate (6-atha) in 2] complex contains two symmetry equivalent $\left\{\mathrm{Mn}_{3}\left(\mu_{3}-\mathrm{O}\right)\right\}$ triangular moieties, which are linked by two phenolate and two oximate oxygen atoms that are related by an inversion centre. Their hexanuclear cores are rather similar to previously reported salicylamidoxime-based $\left[\mathrm{Mn}_{6}\right]$ complexes. ${ }^{13-16}$ The six $\mathrm{Mn}^{\mathrm{III}}$ ions exhibit distorted octahedral geometries with the Jahn-Teller axes approximately perpendicular to the $\left\{\mathrm{Mn}_{3}\left(\mu_{3}-\mathrm{O}\right)\right\}$ planes, with the central $\mathrm{O}^{2-}$ ion displaced $0.04 \AA$ and $0.03 \AA$ above the plane of the $\left[\mathrm{Mn}_{3}\right]$ triangle for $\mathbf{1}$ and 2, respectively. The monodentate carboxylate ligand is coordinate on the $\mathrm{Mn}(1)$ atom in $\mathbf{1}$, on the $\mathrm{Mn}(3)$ atom in 2 and

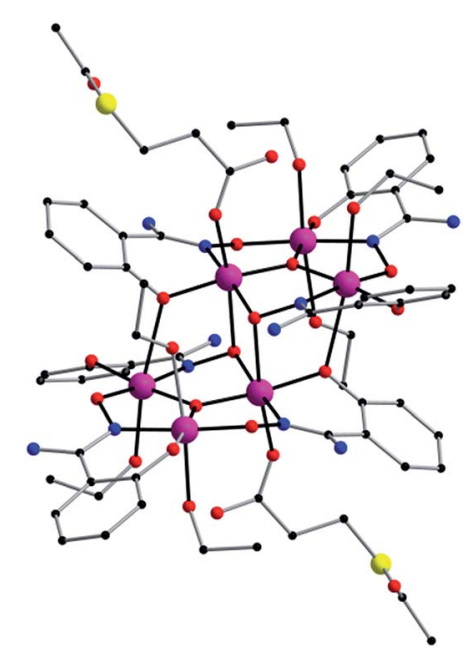

Fig. 1 Perspective view of the molecular structure of the $\left[\mathrm{Mn}_{6}\left(\mu_{3}-\right.\right.$ $\left.\mathrm{O}_{2}\left(\mathrm{H}_{2} \mathrm{~N} \text {-sao }\right)_{6}(3 \text {-atpa })_{2}(\mathrm{EtOH})_{6}\right]$ complex of 1 . $\mathrm{H}$ atoms and solvent molecules of crystallisation have been omitted for clarity [colour code: pink, Mn; yellow, S; red, O; blue, N; black, C].

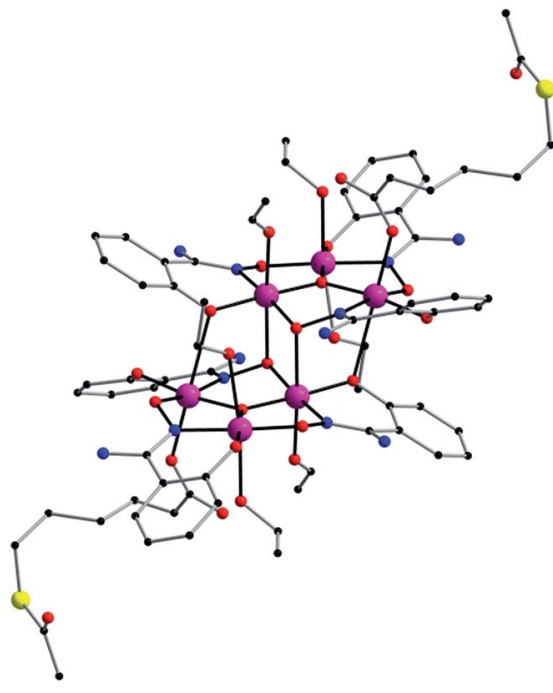

Fig. 2 Perspective view of the molecular structure of the $\left[\mathrm{Mn}_{6}\left(\mu_{3}-\right.\right.$ $\left.\mathrm{O}_{2}\left(\mathrm{H}_{2} \mathrm{~N} \text {-sao }\right)_{6}(6 \text {-atha })_{2}(\mathrm{EtOH})_{6}\right]$ complex of 2 . $\mathrm{H}$ atoms and solvent molecules of crystallisation have been omitted for clarity [colour code: pink, Mn; yellow, S; red, O; blue, N; black, C].

on their symmetry equivalents. The remaining coordination sites are occupied by EtOH molecules. The Mn-N-O-Mn torsion angles of the $\left[\mathrm{Mn}_{3}\left(\mu_{3}-\mathrm{O}\right)\left(\mathrm{H}_{2} \mathrm{~N} \text {-sao }\right)_{3}\right]$ triangular units are 42.6, 30.1 and 27.5 for 1 and 38.9, 36.5 and 26.0 for 2 .

In the crystal packing of 1 and 2 , the neutral $\left[\mathrm{Mn}_{6}\right]$ complexes are mainly connected by hydrogen bonding interactions. In $\mathbf{1}$, the acetylthio groups are $\mathrm{H}$-bonded through the carbonyl to the $-\mathrm{NH}_{2}$ groups on the salicylamidoxime ligands of adjacent $\left[\mathrm{Mn}_{6}\right]$ units ( $\mathrm{O} \cdots \mathrm{N}$ distance, $\sim 3.01 \AA$ ) (see Fig. 3).

Each $\left[\mathrm{Mn}_{6}\right]$ is involved in four of these interactions, linking them into chains that grow along the $c$ axis (Fig. 3). In 2, EtOH molecules sit between neighbouring $\left[\mathrm{Mn}_{6}\right]$ complexes and are

Table 1 Summary of the crystal data for compounds 1 and 2

\begin{tabular}{|c|c|c|}
\hline Compound & 1 & 2 \\
\hline Formula & $\mathrm{C}_{68} \mathrm{H}_{102} \mathrm{O}_{30} \mathrm{~N}_{12} \mathrm{~S}_{2} \mathrm{Mn}_{6}$ & $\mathrm{C}_{82} \mathrm{H}_{134} \mathrm{O}_{32} \mathrm{~N}_{12} \mathrm{~S}_{2} \mathrm{Mn}_{6}$ \\
\hline$M_{\mathrm{r}}$ & 1961.34 & 2193.77 \\
\hline Crystal system & Triclinic & Monoclinic \\
\hline Space group & $P \overline{1}$ & $P 2_{1} / c$ \\
\hline$a / \AA$ & $12.614(1)$ & $15.993(1)$ \\
\hline$b / \AA$ & $13.146(1)$ & $13.559(1)$ \\
\hline$c / \AA$ & $14.873(1)$ & $23.506(1)$ \\
\hline$\alpha /^{\circ}$ & $70.67(1)$ & 90 \\
\hline$\beta /^{\circ}$ & $76.15(1)$ & $97.23(1)$ \\
\hline$\gamma /{ }^{\circ}$ & $66.10(1)$ & 90 \\
\hline$V / \AA^{3}$ & $2111.8(3)$ & $5056.6(2)$ \\
\hline$Z$ & 1 & 2 \\
\hline$D_{\mathrm{c}} / \mathrm{g} \mathrm{cm}^{-3}$ & 1.539 & 1.441 \\
\hline$\mu\left(\mathrm{Mo}-\mathrm{K}_{\alpha}\right) / \mathrm{mm}^{-1}$ & 8.283 & 0.850 \\
\hline$F(000)$ & 1012 & 2296 \\
\hline $\begin{array}{l}\text { Goodness-of-fit } \\
\text { on } F^{2}\end{array}$ & 1.008 & 1.009 \\
\hline$R_{1}[I>2 \sigma(I)]$ & 0.0733 & 0.0751 \\
\hline $\mathrm{w} R_{1}[I>2 \sigma(I)]$ & 0.1887 & 0.1739 \\
\hline
\end{tabular}




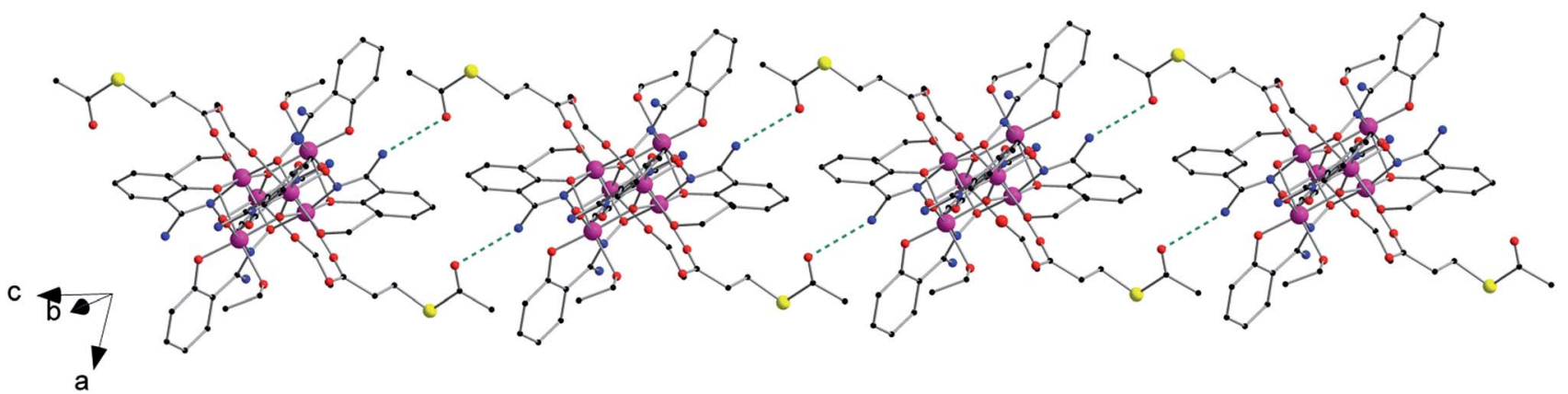

Fig. 3 View of the one-dimensional motif generated by hydrogen bonds ( $\mathrm{N} \cdots \mathrm{O}$ distance, $\sim 3.01 \AA$ ) between the $-\mathrm{NH}_{2}$ and $\mathrm{CH} \mathrm{H}_{3}-\mathrm{C}(\mathrm{O})-\mathrm{S}-\mathrm{groups}$ of adjacent $\left[\mathrm{Mn}_{6}\right]$ units in the crystal of 1 (dashed green lines) [colour code: pink, Mn; yellow, S; red, O; blue, N; black, C].

simultaneously $\mathrm{H}$-bonded to $-\mathrm{NH}_{2}(\mathrm{O} \cdots \mathrm{N}$ distance, $\sim 2.85 \AA)$ and carboxylate $(\mathrm{O} \cdots \mathrm{O}$ distance, $\sim 2.72 \AA)$ groups generating chains that grow along the $c$ axis (Fig. S3†). Intermolecular $\mathrm{S} \cdots \mathrm{S}$ contacts are observed neither in $\mathbf{1}$ nor in 2 , the shortest $\mathrm{S} \cdots \mathrm{S}$ distances being $c a .5 .31 \AA$ (1) and $c a .7 .99$ (2) ̊. Additional weak $\mathrm{C} \cdots \mathrm{C}$ interactions are also observed, in $\mathbf{1}$, between aromatic rings of salicylamidoxime ligands of neighbouring $\left[\mathrm{Mn}_{6}\right]$ complexes $(c a .3 .33 \AA$ ) and, in 2 , between aromatic rings of salicylamidoxime ligands and thioester groups of adjacent $\left[\mathrm{Mn}_{6}\right]$ units ( $c a .3 .67 \AA$ ), which stabilize the supramolecular arrangement in $\mathbf{1}$ and $\mathbf{2}$.

\section{Magnetic properties of 1 and 2}

Dc magnetic susceptibility measurements were performed on microcrystalline samples of 1 and 2 in the $2.0-300 \mathrm{~K}$ temperature range, under an external magnetic field of $0.1 \mathrm{~T}$. The magnetic properties of $\mathbf{1}$ and 2 in the form of $\chi_{M} T v s . T$ plot $\left(\chi_{M}\right.$ being the molar magnetic susceptibility) are shown in Fig. 4. At room temperature the $\chi_{\mathrm{M}} T$ values are $20.0(1)$ and $18.0 \mathrm{~cm}^{3}$ $\mathrm{mol}^{-1} \mathrm{~K}(2)$. Upon cooling, these values approximately follows the Curie law to $c a .100 \mathrm{~K}$ for both compounds. Then, for complex 1, $\chi_{\mathrm{M}} T$ rises gradually with decreasing temperature, reaching a maximum value of $28.0 \mathrm{~cm}^{3} \mathrm{~mol}^{-1} \mathrm{~K}$ at $8.0 \mathrm{~K}$. This feature reveals an intramolecular ferromagnetic coupling between the $\mathrm{Mn}^{\mathrm{III}}$ ions. $\chi_{\mathrm{M}} T$ is then decreasing at lower temperatures. The value of $\chi_{\mathrm{M}} T$ in 2 decreases with decreasing temperature reaching a final value of $c a .6 .5 \mathrm{~cm}^{3} \mathrm{~mol}^{-1} \mathrm{~K}$ at $2.0 \mathrm{~K}$, indicating antiferromagnetic interaction as the resulting magnetic exchange (Fig. 4). The decrease of the $\chi_{\mathrm{M}} T$ for both compounds at lower temperatures is likely due to the presence of intermolecular interactions and/or zero-field splitting (zfs) effects.

These experimental data were treated by using the $2 J$ model described by the Hamiltonian of eqn (1) and Fig. S4, $\uparrow$ affording the parameters: $J_{1}=+0.45 \mathrm{~cm}^{-1}, J_{2}=+0.11 \mathrm{~cm}^{-1}$ and $g=1.99$ for 1 and $J_{1}=+0.86 \mathrm{~cm}^{-1}, J_{2}=-1.14 \mathrm{~cm}^{-1}$ and $g=1.99$ for 2 . This data treatment has satisfactorily been performed in previous works. ${ }^{12}$

$$
\begin{aligned}
\hat{H}= & -2 J_{1}\left(\hat{S_{1}} \hat{S}_{3}+\hat{S_{1}} \hat{S}_{3}+\hat{S}_{1} \hat{S}_{1^{\prime}}+\hat{S}_{1^{\prime}} \hat{S}_{3}+\hat{S}_{1^{\prime}} \hat{S}_{3^{\prime}}\right) \\
& -2 J_{2}\left(\hat{S}_{1} \hat{S}_{2}+\hat{S}_{2} \hat{S}_{3}+\hat{S}_{1^{\prime}} \hat{S}_{2^{\prime}}+\hat{S}_{2^{\prime}} \hat{S}_{3^{\prime}}\right)+\mu_{\mathrm{B}} g H \hat{S}
\end{aligned}
$$

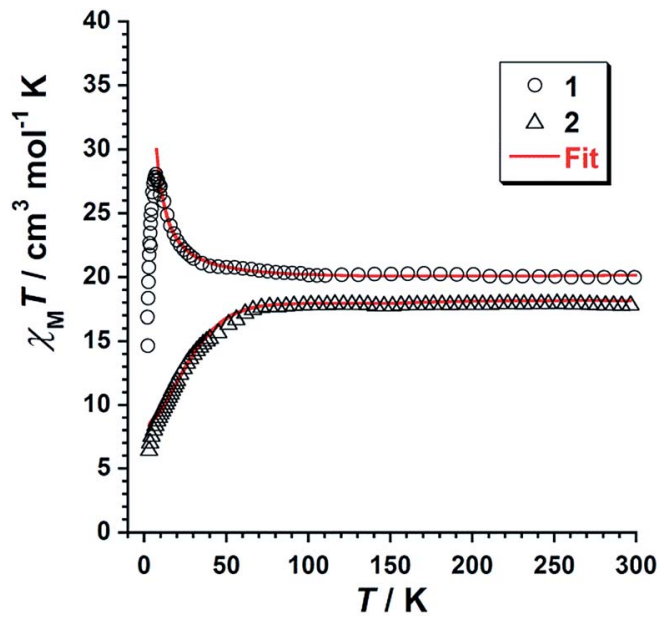

Fig. 4 Plot of $\chi_{M} T$ vs. $T$ obtained from compounds 1 and 2. The solid red line represents the fit of the experimental data obtained for 1 and 2 using the $2 \mathrm{~J}$ model of Hamiltonian (1).

The obtained $J_{1}, J_{2}$ and $g$ values result to be consistent with the torsion angles found in the crystal structures of $\mathbf{1}$ and $\mathbf{2}$, and agree with those previously reported for similar $\left[\mathrm{Mn}_{6}\right]$ systems. ${ }^{12-16}$

In a previous work dealing with DFT studies on salicylamidoxime-based $\left[\mathrm{Mn}_{6}\right]$ complexes, ${ }^{13 c}$ it was established that the critical angle where the exchange pathway between neighbouring $\mathrm{Mn}^{\mathrm{III}}$ ions switches from antiferromagnetic $(J<0)$ to ferromagnetic $(J>0)$ is $c a .27 .0^{\circ}$, which is somewhat lower than that of the related salicylaldoxime-based $\left[\mathrm{Mn}_{6}\right]$ complexes. $^{13 c}$

Our results nicely reflect that fact, given that compound $\mathbf{1}$, with the lowest torsion angle being $27.5^{\circ}$, gave positive $J_{1}$ and $J_{2}$ values indicating a ferromagnetic exchange, whereas in compound 2 , with $26.0^{\circ}$ as the lowest torsion angle, the sign and magnitude of the obtained $J_{2}$ value indicate that the main magnetic exchange is antiferromagnetic. Given that the value of $J_{1}$ (exchange between $\mathrm{Mn}^{\mathrm{III}}$ ions of different $\left[\mathrm{Mn}_{3}\right]$ triangles of the $\left[\mathrm{Mn}_{6}\right]$ unit) is positive in both compounds, what is making the difference to get a $S=4$ or $S=12$ total spin is the value of $J_{2}$ (exchange constant within each trinuclear $\left[\mathrm{Mn}_{3}\right]$ subunit). 
Variable temperature-variable field dc magnetisation data were measured for 1 and 2 in the $2-7 \mathrm{~K}$ temperature and 0.5-7.0 $\mathrm{T}$ field ranges. The experimental data are given as reduced magnetisation in Fig. 5 and 6. These data do not reach the saturation values, maybe because excited states with lowest spins are also populated. Anyway, they were well fitted to a Zeeman plus axial zero-field splitting Hamiltonian $\left[\hat{H}=D\left(\hat{S}_{z}^{2}\right.\right.$ $-S(S+1) / 3)+\mu_{\mathrm{B}} g H \hat{S}$, where $D$ is the axial anisotropy of the $\left[\mathrm{Mn}_{6}\right]$ cluster, $\mu_{\mathrm{B}}$ is the Bohr magneton, $\hat{S}_{z}$ is the easy-axis spin operator and $H$ is the applied field] assuming only the ground state is populated. ${ }^{12}$ The best fits afforded the parameters $S=12, g=1.98$ and $D=-0.44 \mathrm{~cm}^{-1}$ for 1 and $S=4, g=2.00$ and $D=-0.98 \mathrm{~cm}^{-1}$ for 2 , which are in line with other members of the $\left[\mathrm{Mn}_{6}\right]$ family. ${ }^{12-16}$ Besides the results obtained by fitting the experimental data of the reduced magnetisation, ground state spin values of $S=12$ (1) and $S=4$ (2) were also obtained

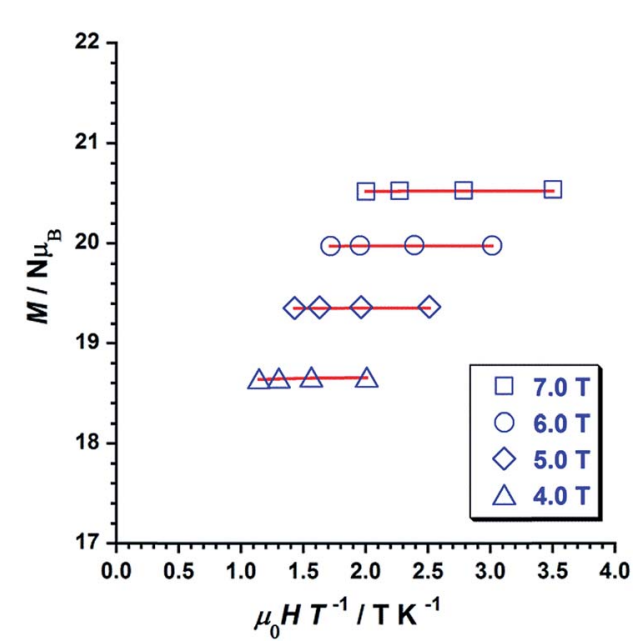

Fig. 5 Plot of the reduced magnetisation $\left(M / N \mu_{\mathrm{B}}\right.$ vs. $\left.\mu_{0} H / T\right)$ for 1 in 4 , 5,6 and $7 \mathrm{~T}$ fields and temperatures $2-5 \mathrm{~K}$. The solid lines represent the best fit of the experimental data.

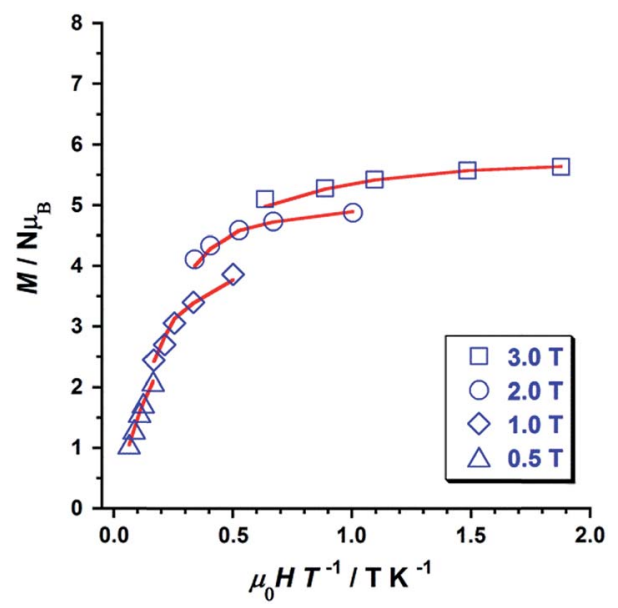

Fig. 6 Plot of the reduced magnetisation $\left(M / N \mu_{B} v s . \mu_{0} H / T\right)$ for 2 in $0.5,1,2$ and $3 \mathrm{~T}$ fields and temperatures $2-5 \mathrm{~K}$. The solid lines represent the best fit of the experimental data. from dc susceptibility measurements. Indeed, plots of the energy versus total spin, extracted from the isotropic simulation of the magnetic susceptibility, are shown in Fig. 7 and 8 for 1 and 2, respectively. The first excited state found in 1 is a $S=11$ located at $1.75 \mathrm{~cm}^{-1}$, and the first excited state in 2 is a $S=3$ located at $0.85 \mathrm{~cm}^{-1}$ (Fig. 7 and 8 ).

Ac susceptibility measurements were performed on samples of 1 and 2 in the temperature range 2-8 K, in zero applied dc field and a $3.9 \mathrm{G}$ ac field oscillating in the $5-1000 \mathrm{~Hz}$ range of frequencies. Out-of-phase ac signals $\left(\chi^{\prime \prime}{ }_{\mathrm{M}}\right)$ for $\mathbf{1}$ and $\mathbf{2}$ are shown in Fig. 9 (1) and Fig. 10 (2), which exhibit frequency dependence of the $\chi^{\prime \prime}{ }_{M}$ maxima. This feature is consistent with SMM behaviour. In 2 , it is observed that the $\chi^{\prime \prime}{ }_{M}$ maxima decrease with decreasing frequency, which is a peculiarity typical of strong intermolecular interactions in single-molecule and chain magnets (SMMs and SCMs). ${ }^{17,18}$

We fitted these data to the Arrhenius equation $\left[\tau=\tau_{\mathrm{o}^{-}}\right.$ $\exp \left(U_{\text {eff }} / k_{\mathrm{B}} T\right)$, where $\tau_{\mathrm{o}}$ is the pre-exponential factor, $\tau$ is the relaxation time, $U_{\text {eff }}$ is the barrier to relaxation of the magnetisation and $k_{\mathrm{B}}$ is the Boltzmann constant]. The inset of the Fig. 9

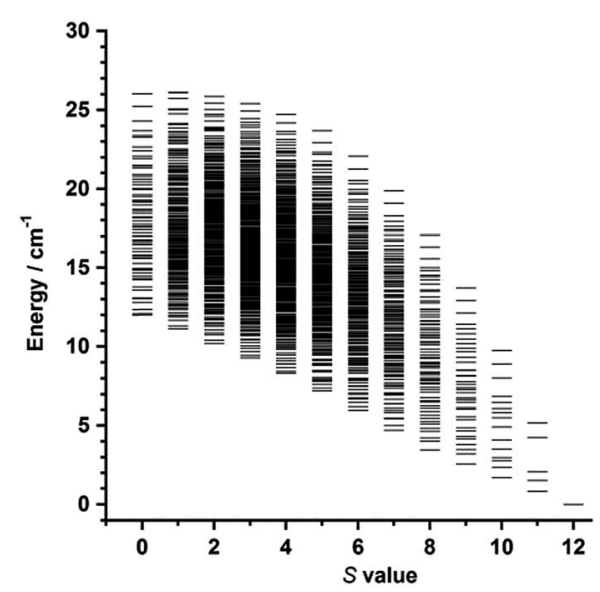

Fig. 7 Plot of energy versus total spin state, extracted from the isotropic simulation of the susceptibility data, for 1.

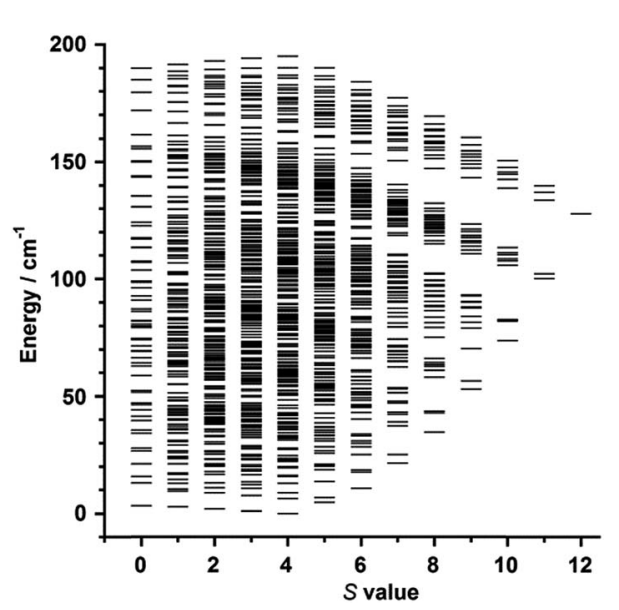

Fig. 8 Plot of energy versus total spin state, extracted from the isotropic simulation of the susceptibility data, for 2 . 


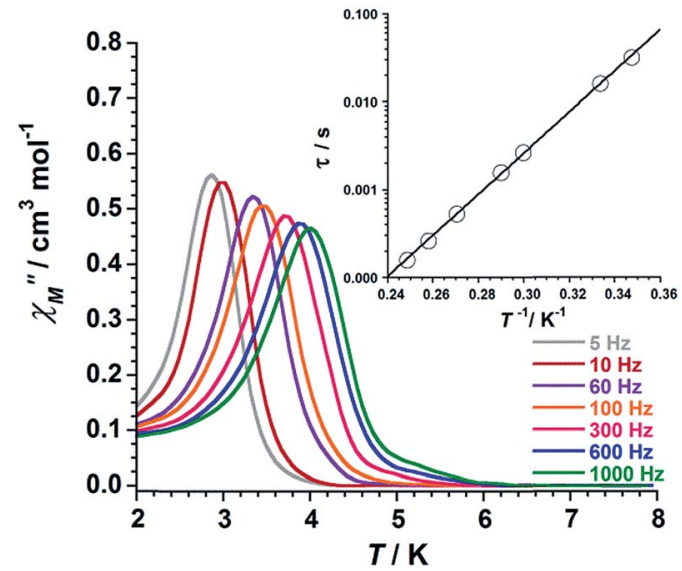

Fig. 9 Out-of-phase ac susceptibility $\left(\chi_{M}^{\prime \prime}\right)$ versus $T$ plot for 1 . The inset shows the Arrhenius best-fit plot (see text).

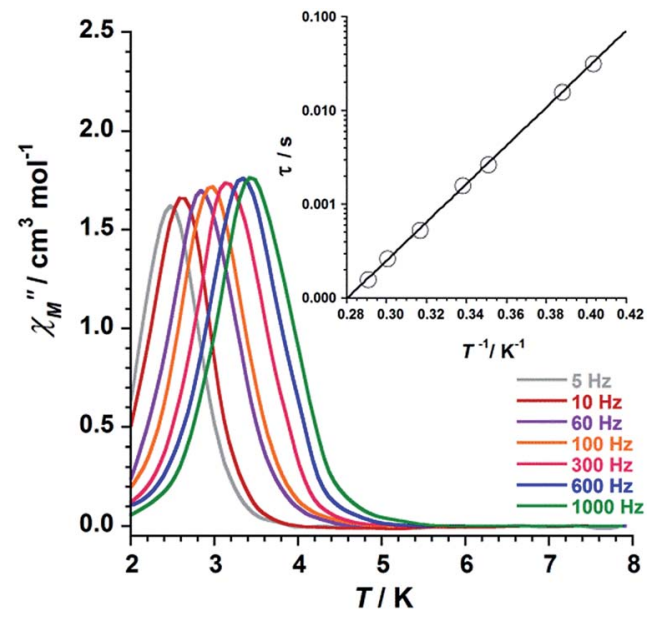

Fig. 10 Out-of-phase ac susceptibility $\left(\chi_{M}^{\prime \prime}\right)$ versus $T$ plot for 2 . The inset shows the Arrhenius best-fit plot (see text).

(1) and Fig. 10 (2) shows these Arrhenius plots. The obtained values for $\tau_{\mathrm{o}}$ and $U_{\text {eff }}$ are $2.6 \times 10^{-10} \mathrm{~s}$ and $54.0 \mathrm{~K}$ for 1 and $1.9 \times 10^{-10} \mathrm{~s}$ and $47.0 \mathrm{~K}$ for 2 , respectively. These $U_{\text {eff }}$ values for 1 and 2 fall into the range $\left(24.0 \mathrm{~K}<U_{\text {eff }}<86.0 \mathrm{~K}\right)$ for previously reported salicylamidoxime-based $\left[\mathrm{Mn}_{6}\right]$ complexes. ${ }^{\mathbf{1 3 - 1 6}}$

\section{Conclusions}

In summary, the crystal structures and magnetic behaviour of two novel $\left[\mathrm{Mn}_{6}\right]$ single-molecule magnets (SMMs) of formula $\left[\mathrm{Mn}_{6}\left(\mu_{3}-\mathrm{O}\right)_{2}\left(\mathrm{H}_{2} \mathrm{~N}-\mathrm{saO}\right)_{6}(3 \text {-atpa })_{2}(\mathrm{EtOH})_{6}\right] \cdot 2 \mathrm{EtOH} \cdot 2 \mathrm{H}_{2} \mathrm{O}$ (1) and $\left[\mathrm{Mn}_{6}\left(\mu_{3}-\mathrm{O}\right)_{2}\left(\mathrm{H}_{2} \mathrm{~N}-\mathrm{saO}\right)_{6}(6-\mathrm{atha})_{2}(\mathrm{EtOH})_{6}\right] \cdot 6 \mathrm{EtOH}(2)\left[\mathrm{H}_{2} \mathrm{~N}-\mathrm{saOH}_{2}\right.$ $=$ salicylamidoxime, 3-hatpa $=3$-(acetylthio)propionic acid, 6hatha $=6$-(acetylthio)hexanoic acid] have been reported. 1 and 2 are the first examples of thioester-functionalised complexes in the coordination chemistry of oxime-based $\left[\mathrm{Mn}_{6}\right]$ SMMs, these structures also being the first reported complexes containing the 3-(acetylthio)propionate (3-atpa) and 6-(acetylthio)hexanoate (6-atha) ligands. Such features, together with their relative stability, make 1 and 2 suitable SMMs to be studied on devices in the field of molecular spintronics. Indeed, we believe that our compounds could be adequate systems to be connected to junction devices. This investigation is underway.

\section{Experimental}

\section{Materials and physical measurements}

All manipulations were performed under aerobic conditions, using chemicals as received from Sigma-Aldrich. Elemental analyses (C, H, and N) were performed by the Central Service for the Support to Experimental Research (SCSIE) at the University of Valencia. Infrared spectra of $\mathbf{1}$ and $\mathbf{2}$ were recorded as $\mathrm{KBr}$ pellets using a PerkinElmer Spectrum 65 FT-IR spectrometer in the $4000-400 \mathrm{~cm}^{-1}$ region. Dc and ac magnetic susceptibility measurements on microcrystalline samples of $\mathbf{1}$ and $\mathbf{2}$ were carried out on a Quantum Design MPMS-XL SQUID magnetometer. The dc studies were performed in the temperature range of 2-300 $\mathrm{K}$ in an applied magnetic field of $0.1 \mathrm{~T}$. The ac susceptibility measurements were performed in zero applied dc field and a $3.9 \mathrm{G}$ ac oscillating field with temperature and frequency ranges of 2-8 $\mathrm{K}$ and 5-1000 $\mathrm{Hz}$, respectively. Diamagnetic corrections were applied to the observed paramagnetic susceptibilities using Pascal's constants. ${ }^{19,20}$

\section{Preparation of the complexes}

1. $\mathrm{MnCl}_{2} \cdot 4 \mathrm{H}_{2} \mathrm{O}(0.594 \mathrm{~g}, 3.0 \mathrm{mmol})$ was added dropwise and with constant stirring to a solution formed by $\mathrm{H}_{2} \mathrm{~N}-\mathrm{SaOH}_{2}$ (0.456 g, $3.0 \mathrm{mmol})$ and 3-acetylthiopropionic acid (1.0 g, $6.8 \mathrm{mmol})$ in $\mathrm{EtOH}(100 \mathrm{~mL})$, then $\mathrm{NEt}_{3}(2.0 \mathrm{~mL}, 3.58 \mathrm{mmol})$ was added. After stirring for $1 \mathrm{~h}$ a dark green solution was generated and left to evaporate at room temperature. A dark green microcrystalline solid was formed in 1 day, separated by filtration and washed with EtOH and ether. Yield: $84 \%$. Suitable crystals for X-ray diffraction studies were formed by layering a concentrated acetone solution of the microcrystalline solid with EtOH. Anal. calcd (found) for $\mathrm{C}_{68} \mathrm{H}_{102} \mathrm{O}_{30} \mathrm{~N}_{12} \mathrm{~S}_{2} \mathrm{Mn}_{6}$ (1): C, 41.6 (41.5); H, 5.2 (4.9); N, 8.6 (9.0)\%. Selected IR peaks (in $\mathrm{KBr}, \mathrm{cm}^{-1}$ ): $3332 \mathrm{~m}, 1605 \mathrm{vs}, 1575 \mathrm{~m}, 1530 \mathrm{~s}, 1481 \mathrm{~m}, 1439 \mathrm{~m}$, $1420 \mathrm{~m}, 1315 \mathrm{~s}, 1253 \mathrm{~s}, 1146 \mathrm{~m}, 1023 \mathrm{~s}, 881 \mathrm{~s}, 757 \mathrm{~m}, 684 \mathrm{vs}, 649 \mathrm{~m}$, 579w, 474w.

2. Complex 2 was prepared as $\mathbf{1}$ but by using 6-acetylthiohexanonic acid (1.0 mL, $6.0 \mathrm{mmol})$ instead of 3-acetylthiopropionic acid. Yield: $77 \%$. A concentrated ethanolic solution of 2 was layered with the same solvent to give suitable crystals by slow diffusion. Anal. calcd (found) for $\mathrm{C}_{82} \mathrm{H}_{134} \mathrm{O}_{32} \mathrm{~N}_{12} \mathrm{~S}_{2} \mathrm{Mn}_{6}$ (2): C, 44.9 (45.1); H, 6.2 (5.9); N, 7.7 (8.1)\%. Selected IR peaks (in $\mathrm{KBr} / \mathrm{cm}^{-1}$ ): $3326 \mathrm{~m}, 2928 \mathrm{~m}, 1604 \mathrm{vs}, 1574 \mathrm{~m}, 1527 \mathrm{~s}, 1482 \mathrm{~m}$, $1440 \mathrm{~m}, 1418 \mathrm{~m}, 1317 \mathrm{~s}, 1254 \mathrm{~s}, 1146 \mathrm{~m}, 1023 \mathrm{~s}, 883 \mathrm{~s}, 750 \mathrm{~m}, 686 \mathrm{vs}$, 648m, 579w, 553w, 474w.

\section{$\mathrm{X}$-ray data collection and structure refinement}

$\mathrm{X}$-ray diffraction data on single crystals of $\mathbf{1}$ and $\mathbf{2}$ were collected on a Rigaku Oxford Diffraction SuperNova diffractometer with graphite-monochromated and $\mathrm{Cu}-\mathrm{K}_{\alpha}$ radiation $(\lambda=1.54184 \AA)$ for 1 and $\mathrm{Mo}^{-} \mathrm{K}_{\alpha}$ radiation $(\lambda=0.71073 \AA)$ for 2 . Crystal 
parameters and refinement results are summarized in Table 1. The structures of $\mathbf{1}$ and $\mathbf{2}$ were solved by direct methods and subsequently completed by Fourier recycling using the SHELXTL ${ }^{21-23}$ software packages. The final full-matrix leastsquares refinements on $F^{2}$, minimising the function $\sum \mathcal{w}\left(\left|F_{\mathrm{o}}\right|-\left|F_{\mathrm{c}}\right|\right)^{2}$, reached convergence with the values of the discrepancy indices given in Table 1. Disorder of free solvent molecules was detected in both compounds (1 and 2). The graphical manipulations were performed with the DIAMOND program. ${ }^{24}$ CCDC 1568972 (1) and 1568973 (2).†

\section{Conflicts of interest}

There are no conflicts to declare.

\section{Acknowledgements}

Financial support from the Spanish Ministry of Economy and Competitiveness (MINECO) with projects CTQ2016-75068-P and MDM-2015-0538 (Excellence Unit “María de Maeztu”) is gratefully acknowledged. J. M. L. thanks the Spanish MINECO for a "Ramón y Cajal" researcher contract.

\section{Notes and references}

1 L. Bogani and W. Wernsdorfer, Nat. Mater., 2008, 7, 179-186. 2 T. Komeda, H. Isshiki, J. Liu, Y.-F. Zhang, N. Lorente, K. Katoh, B. K. Breedlove and M. Yamashita, Nat. Commun., 2011, 2, 217.

3 J. M. Clemente-Juan, E. Coronado and A. Gaita-Ariño, Chem. Soc. Rev., 2012, 41, 7464-7478.

4 J. Ferrando-Soria, J. Vallejo, M. Castellano, J. Martínez-Lillo, E. Pardo, J. Cano, I. Castro, F. Lloret, R. Ruiz-García and M. Julve, Coord. Chem. Rev., 2017, 339, 17-103.

5 D. Li, S. Parkin, R. Clérac and S. M. Holmes, Inorg. Chem., 2006, 45, 7569-7571.

6 L. Gregoli, C. Danieli, A.-L. Barra, P. Neugebauer, G. Pellegrino, G. Poneti, R. Sessoli and A. Cornia, Chem.Eur. J., 2009, 15, 6456-6467.

7 (a) F. Moro, V. Corradini, M. Evangelisti, V. De Renzi, R. Biagi, U. del Pennino, C. J. Milios, L. F. Jones and E. K. Brechin, J. Phys. Chem. B, 2008, 112, 9729-9735; (b) F. Totti, G. Rajaraman, M. Iannuzzi and R. Sessoli, J. Phys. Chem. C, 2013, 117, 7186-7190.

8 F. Moro, V. Corradini, M. Evangelisti, R. Biagi, V. De Renzi, U. del Pennino, J. C. Cezar, R. Inglis, C. J. Milios and E. K. Brechin, Nanoscale, 2010, 2, 2698-2703.

9 P. Tyagi, D. Li, S. M. Holmes and B. J. Hinds, J. Am. Chem. Soc., 2007, 129, 4929-4938.

10 (a) A. Cornia, A. C. Fabretti, M. Pacchioni, L. Zobbi, D. Bonacchi, A. Caneschi, D. Gatteschi, R. Biagi, U. Del Pennino, V. De Renzi, L. Gurevich and H. S. J. Van der Zant, Angew. Chem., Int. Ed., 2003, 42, 1645-1648; (b) M. Mannini, F. Pineider, Ph. Sainctavit, C. Danieli, E. Otero, C. Sciancalepore, A. M. Talarico, M.-A. Arrio, A. Cornia, D. Gatteschi and R. Sessoli, Nat. Mater., 2009, 8,
194-197; (c) M. Mannini, F. Pineider, C. Danieli, F. Totti, L. Sorace, Ph. Sainctavit, M.-A. Arrio, E. Otero, L. Joly, J. C. Cezar, A. Cornia and R. Sessoli, Nature, 2010, 468, 417-421; (d) E. Tancini, M. Mannini, Ph. Sainctavit, E. Otero, R. Sessoli and A. Cornia, Chem.-Eur. J., 2013, 19, 16902-16905.

11 S. Wagner, F. Kisslinger, S. Ballmann, F. Schramm, R. Chandrasekar, T. Bodenstein, O. Fuhr, D. Secker, K. Fink, M. Ruben and H. B. Weber, Nat. Nanotechnol., 2013, 8, 575-579.

12 (a) C. J. Milios, C. P. Raptopoulou, A. Terzis, F. Lloret, R. Vicente, S. P. Perlepes and A. Escuer, Angew. Chem., Int. Ed., 2004, 43, 210-212; (b) C. J. Milios, A. Vinslava, P. A. Wood, S. Parsons, W. Wernsdorfer, G. Christou, S. P. Perlepes and E. K. Brechin, J. Am. Chem. Soc., 2007, 129, 8-9; (c) C. J. Milios, A. Vinslava, W. Wernsdorfer, S. Moggach, S. Parsons, S. P. Perlepes, G. Christou and E. K. Brechin, J. Am. Chem. Soc., 2007, 129, 2754-2755; (d) C. J. Milios, A. Vinslava, W. Wernsdorfer, A. Prescimone, P. A. Wood, S. Parsons, S. P. Perlepes, G. Christou and E. K. Brechin, J. Am. Chem. Soc., 2007, 129, 6547-6561; (e) C. J. Milios, R. Inglis, R. Bagai, W. Wernsdorfer, A. Collins, S. Moggach, S. Parsons, S. P. Perlepes, G. Christou and E. K. Brechin, Chem. Commun., 2007, 3476-3478; (f) C. J. Milios, R. Inglis, A. Vinslava, R. Bagai, W. Wernsdorfer, S. Parsons, S. P. Perlepes, G. Christou and E. K. Brechin, J. Am. Chem. Soc., 2007, 129, 12505-12511; (g) C. J. Milios, S. Piligkos and E. K Brechin, Dalton Trans., 2008, 1809-1817; (h) R. Inglis, C. J. Milios, L. F. Jones, S. Piligkos and E. K. Brechin, Chem. Commun., 2012, 48, 181-190.

13 (a) A.-R. Tomsa, J. Martínez-Lillo, Y. Li, L.-M. Chamoreau, K. Boubekeur, F. Farias, M. A. Novak, E. Cremades, E. Ruiz, A. Proust, M. Verdaguer and P. Gouzerh, Chem. Commun., 2010, 46, 5106-5108; (b) G.-Y. An, A.-L. Cui and H.-Z. Kou, Inorg. Chem. Commun., 2011, 14, 1475-1478; (c) J. Martínez-Lillo, A.-R. Tomsa, Y. Li, L.-M. Chamoreau, E. Cremades, E. Ruiz, A.-L. Barra, A. Proust, M. Verdaguer and P. Gouzerh, Dalton Trans., 2012, 41, 13668-13681; (d) J. Martínez-Lillo, L.-M. Chamoreau, A. Proust, M. Verdaguer and P. Gouzerh, C. R. Chim., 2012, 15, 889-894. 14 J. Martínez-Lillo, N. Dolan and E. K. Brechin, Dalton Trans., 2013, 42, 12824-12827.

15 J. Martínez-Lillo, N. Dolan and E. K. Brechin, Dalton Trans., 2014, 43, 4408-4414.

16 J. Martínez-Lillo, J. Cano, W. Wernsdorfer and E. K. Brechin, Chem.-Eur. J., 2015, 21, 8790-8798.

17 L. M. Toma, R. Lescouëzec, J. Pasán, C. Ruiz-Pérez, J. Vaissermann, J. Cano, R. Carrasco, W. Wernsdorfer, F. Lloret and M. Julve, J. Am. Chem. Soc., 2006, 128, 48424853.

18 L. M. Toma, C. Ruiz-Pérez, J. Pasán, W. Wernsdorfer, F. Lloret and M. Julve, J. Am. Chem. Soc., 2012, 134, 1526515268.

19 A. Earnshaw, Introduction to Magnetochemistry, Academic Press, London, Kahn, 1968.

20 G. A. Bain and J. F. Berry, J. Chem. Educ., 2008, 85, 532-536. 
21 G. M. Sheldrick, Acta Crystallogr., Sect. A: Found. Crystallogr., 2008, 64, 112.

22 G. M. Sheldrick, Acta Crystallogr., Sect. C: Struct. Chem., 2015, 24 DIAMOND. 3.2d, Crystal Impact GbR, CRYSTAL IMPACT; K. 71, 3-8.
23 SHELXTL, Bruker Analytical X-ray Instruments, Madison, WI, 1998.

Bra. 